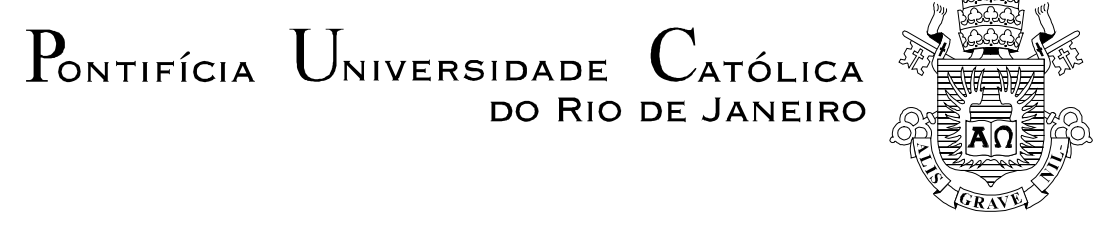

Antonio Gutiérrez Merma

Aspectos Fundamentais da Bioflotação do Sistema Apatita Quartzo usando a bactéria Rhodococcus opacus como Biorreagente

Tese de Doutorado

Tese apresentada como requisito parcial para obtenção do título de Doutor pelo Programa de PósGraduação em Engenharia de Materiais e de Processos Químicos e Metalúrgicos da PUC-Rio.

Orientador: Prof. Mauricio Leonardo Torem

Rio de Janeiro

Março de 2012 


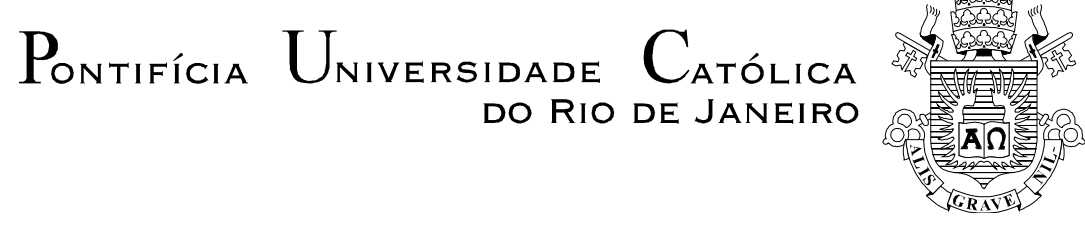

Antonio Gutiérrez Merma

\section{Aspectos Fundamentais da Bioflotação do Sistema Apatita Quartzo usando a bactéria Rhodococcus opacus como Biorreagente}

Tese apresentada como requisito parcial para obtenção do grau de Doutor pelo Programa de Pós-Graduação em Engenharia de Materiais e de Processos Químicos e Metalúrgicos do Departamento de Engenharia de Materiais do Centro Técnico Científico da PUC-Rio. Aprovada pela Comissão Examinadora abaixo assinada.

Prof. Mauricio Leonardo Torem

Orientador

Departamento de Engenharia de Materiais - PUC-Rio

Prof. Roberto José de Carvalho

Departamento de Engenharia de Materiais - PUC-Rio

Prof. Francisco José Moura

Departamento de Engenharia de Materiais - PUC-Rio

Dr. Reiner Neuman

Centro de Tecnologia Mineral - CETEM

Dra. Silvia C. Alvez França

Centro de Tecnologia Mineral - CETEM

Prof. José Eugenio Leal Coordenador(a) Setorial do Centro

Técnico Científico - PUC-Rio

Rio de Janeiro, 28 de março de 2012 
Todos os direitos reservados. É proibida a reprodução total ou parcial do trabalho sem autorização da universidade, do autor e do orientador.

\section{Antonio Gutierrez Merma}

Antonio Gutiérrez Merma possui graduação em Engenharia Química - Universidade Nacional de Sán Agustín (2003), mestrado no Departamento de Engenharia de Materiais do CTC da PUC-Rio (2008). Cursa, no momento, o doutorado na mesma universidade. Tem experiência na área de Engenharia de Materiais e Metalúrgica, com ênfase em Hidrometalurgia e Tratamento de Minérios. Atua, principalmente, nos seguintes temas: Eletrocoagulação, Tratamento de efluentes líquidos, Flotação e Biotecnologia Mineral e Ambiental.

Ficha Catalográfica

Gutiérrez Merma, Antonio

Aspectos Fundamentais da bioflotação do sistema Apatita - Quartzo usando a bactéria Rhodococcus opacus como biorreagente/ Antonio Gutiérrez Merma; Orientador: Mauricio Leonardo Torem.- 2012

145 f. : il. (color.) ; $30 \mathrm{~cm}$

Tese (doutorado)-Pontifícia Universidade Católica do Rio de Janeiro, Departamento de Engenharia de Materiais, 2012.

Inclui bibliografia

1. Engenharia de materiais - Teses. 2. Bioflotação. 3. Biorreagentes. 4. Fosfatos. 5. Apatita. I. Torem, Mauricio Leonardo. II. Pontifícia Universidade Católica do Rio de Janeiro. Departamento de Engenharia de Materiais. III. Título.

CDD: 620.11 
Aos meus pais, Juan Mario Antonio Gutiérrez Rodriguez e Gladys Balbina Merma Cardenas, a Andressa Damascena de Oliveira e em especial ao meu querido filho João Antonio. 


\section{Agradecimentos}

Agradeço a Deus por me iluminar e me dar forças para conseguir andar dia a dia do lado das pessoas que mais amo.

Agradeço ao meu orientador Mauricio Leonardo Torem pelo apoio e confiança depositada, aos professores do Departamento de Engenharia de Materiais da Pontifícia Universidade Católica de Rio de Janeiro - PUC-Rio.

Meu agradecimento especial ao CNPq e à FAPERJ pelo apoio financeiro durante o meu curso de Doutorado.

Ao Doutor Reiner Neumann e à Doutora Marisa Bezerra de Mello Monte do Centro de Tecnologia Mineral - CETEM pela grande colaboração e ensino fornecidos, além do uso de instalações laboratoriais.

Aos colegas Ronald Rojas Hacha, Fabiano Faulstich, Josimar Firmino de Lima, Edvaldo da Conceição Silva, Antonieta Middea, Jean Abbud da Silva, Raquel Zácaron e funcionários do CETEM pelo apoio concedido.

Agradeço a Thais de Lima Alves Pinheiro Fernandes pela ajuda na análise semiquantitativa das amostras de apatita.

Agradeço a Karla Mota pela ajuda na preparação das amostras de bactéria e mineral a serem observadas no microscópio eletrônico.

Aos meus queridos amigos da casa XXI, amigos do departamento DEMa e de outros departamentos da PUC-Rio.

Aos meus pais, irmãos e sobrinhos pelo apoio, suporte e carinho demonstrado.

Agradecimento especial à minha querida Andressa Damascena, mãe do meu filho, pelo amor e paciência de sempre. 


\section{Resumo}

Merma, Antonio Gutiérrez; Torem, Mauricio Leonardo. Aspectos Fundamentais da Bioflotação do sistema Apatita - Quartzo usando a bactéria Rhodococcus opacus como biorreagente. Rio de Janeiro, 2012. 145p. Tese de Doutorado - Departamento de Engenharia de Materiais, Pontifícia Universidade Católica do Rio de Janeiro.

Diversos microrganismos como bactérias, fungos e/ou seus produtos metabólicos tem sido usados como biorreagentes no bioprocessamento mineral. Um microrganismo hidrofóbico pode mudar as características hidrofílicas de uma superfície mineral se ele aderir na superfície do mineral. Esse é o caso da bactéria Rhodococcus opacus, com características hidrofóbicas identificadas em pesquisas anteriores. Neste trabalho é estudado o comportamento eletroforético e microflotação do sistema mineral quartzo - apatita (apatita “ $A$ ” e apatita “ $B$ ”) após interação com células da bactéria. Os resultados mostraram uma mudança no perfil de potencial zeta das amostras minerais após interação com a bactéria, essa mudança foi mais significativa nas apatitas que no quartzo. Os resultados também mostraram que a adesão das células bacterianas na superfície mineral pode ser através de interações especificas além de interações eletrostáticas. Foi observado que a bactéria em suspensão consegue reduzir a tensão superficial da interface ar/água de $70 \mathrm{mN} / \mathrm{m}$ até valores próximos de $54 \mathrm{mN} / \mathrm{m}, 55 \mathrm{mN} / \mathrm{m}$ e $56 \mathrm{mN} / \mathrm{m}$ para valores de $\mathrm{pH}$ de 3,5 , e 7 , respectivamente, faixa de $\mathrm{pH}$ na qual foi observada a maior produção de espuma. O valor máximo de flotabilidade para todas as amostras minerais foi obtido num valor de $\mathrm{pH}$ ao redor de 5; sendo que para a apatita " $B$ " alcançou em torno de $90 \%$ de flotabilidade usando 0,15 g.L $L^{-1}$ de bactéria e com 5 minutos de flotação, enquanto a apatita " $A$ " precisou de 0,20 g.L $\mathrm{L}^{-1}$ de bactéria para alcançar a mesma recuperação, finalmente no caso do quartzo o valor foi próximo de $13 \%$ com 0,15 g.L $\mathrm{L}^{-1}$ de bactéria e sob as mesmas condições de trabalho. A adaptação da bactéria a substrato mineral revelou uma mudança no comportamento da bactéria durante o processo de flotação e foi observada uma maior flotabilidade da apatita num valor de $\mathrm{pH}$ em torno de 3 após adaptação ao mineral apatita. Já no caso do quartzo observou-se um leve incremento na flotabilidade em todos os valores de $\mathrm{pH}$. A bioflotação de apatita e quartzo segue modelos cinéticos de primeira ordem. Observou-se que as constantes de taxa $\left(\mathrm{K}_{1}\right)$ da flotação de apatita “ $A$ ” diminuem com reduções de 
tamanho de partícula, mudando de 0,429 $\left(\mathrm{min}^{-1}\right)$ para 0,198 $\left(\mathrm{min}^{-1}\right)$ quando o tamanho passou de $(106$ - 150) $\mu \mathrm{m}$ para $(38$ - 75) $\mu \mathrm{m}$, no caso da apatita “ $B$ ” essa redução foi de $0,518\left(\mathrm{~min}^{-1}\right)$ para $0,295\left(\mathrm{~min}^{-1}\right)$, o contrário foi observado no caso do quartzo incrementando de $0,016 \min ^{-1}$ para $0,11 \mathrm{~min}^{-1}$. Os estudos fundamentais de mobilidade eletroforética e flotabilidade apoiados pela microscopia eletrônica de varredura evidenciaram a seletividade na separação de apatita e quartzo e deste modo ratificaram o potencial uso da bactéria Rhodococcus opacus como biorreagente no processamento mineral.

\section{Palavras-chave}

Bioflotação; biorreagentes; fosfatos; apatita; quartzo. 


\section{Abstract}

Merma, Antonio Gutiérrez; Torem, Mauricio Leonardo (Advisor). Fundamental aspects of Apatite and Quartz bioflotation using the Rhodococcus opacus bacterium as a bioreagent. Rio de Janeiro, 2012. 145p. PhD thesis - Departamento de Engenharia de Materiais, Pontifícia Universidade Católica do Rio de Janeiro.

Microorganisms, bacteria, fungi and/or their metabolic products have been used as biorreagents in mineral processing. A hydrophobic microorganism should render a hydrophilic mineral surface somewhat hydrophobic if these attach to the mineral. It's the case of the Rhodococcus Opacus strain, which hydrophobic behavior was proved in others works. In this work, we studied the electrophoretic behavior and the microflotation response of the apatite-quartz system after interaction with bacterial cells. The zeta potential results showed a change in the profile of the minerals after the bacterial interaction, this change was more significant in apatite than in quartz. These results also suggest that the bacterial adhesion in the minerals surface was not for electrostatic interactions. It was observed that the bacterial reduced the interfacial tension from air/water from 70 $\mathrm{mN} / \mathrm{m}$ to $54 \mathrm{mN} / \mathrm{m}, 55 \mathrm{mN} / \mathrm{m}$ and $56 \mathrm{mN} / \mathrm{m}$ for suspensions with values of $\mathrm{pH} 3$, 5 and 7 respectively, values where the higher quantity of foam was formed. The higher flotabilities of all minerals used was recorded in $\mathrm{pH}$. The green apatite flotability achieved a value around $90 \%$ with $150 \mathrm{mg} . \mathrm{L}^{-1}$ of bacterial after 5 minutes of flotation, while the blue apatite needed $200 \mathrm{mg} . \mathrm{L}^{-1}$ of the bacterial to achieve the same flotability under the same experimental conditions. On the other hand, the quartz flotability had a value around $13 \%$, with $150 \mathrm{mg} . \mathrm{L}^{-1}$ of bacteria and after 5 minutes of flotation. The bacterial adaptation to mineral substrate revealed a change in the bacterial behavior during the flotation process; it was observed a higher apatite flotability in $\mathrm{pH} 3$ after the adaptation of the bacterial to apatite as substrate. The quartz flotability also showed a small increase in all the $\mathrm{pH}$ range studied. The mineral flotability followed the first order kinetics model, the rate constants $(\mathrm{K})$ for the blue apatite flotability underwent a reduction with small particles size, changing from $0,429\left(\mathrm{~min}^{-1}\right)$ to $0,198\left(\mathrm{~min}^{-1}\right)$ when the particle size was altered from $(106-150) \mu \mathrm{m}$ to $(38-75) \mu \mathrm{m}$, while the rate constants for the green apatite flotability changed from $0,518\left(\mathrm{~min}^{-1}\right)$ to 0,295 $\left(\mathrm{min}^{-1}\right)$. Finally the rate constants of the quartz flotability suffer an increased from 
$0,016 \mathrm{~min}^{-1}$ to $0,11 \mathrm{~min}^{-1}$. The fundamental electroforetic and flotation studies together to the Scanning electron microscopy showed a selectivity bioflotation in the apatite-quartz system, demonstrating in this way the potential that Rhodococcus opacus as a biocollector and its possible application in phosphate flotation industry.

\section{Keywords:}

Bioflotation; bioreagents; phosphates; apatite; quartz. 


\section{Sumário}

1. Introdução

2. Objetivos e relevância do trabalho

23

2.1. Objetivo Geral 23

2.2. Objetivos Específicos 23

2.3. Relevância do trabalho 24

3. Revisão da Literatura 25

3.1. Minerais de apatita 25

3.2. Minérios Fosfáticos Brasileiros $\quad 27$

3.3. Beneficiamento de Minérios fosfáticos 29

3.4. Carga superficial de superfície mineral 35

3.4.1. Potencial Zeta da Apatita 37

3.4.2. Potencial zeta do quartzo 41

3.5. Bioflotação Mineral 42

3.5.1. Caracterização dos microrganismos 46

3.5.2. Uso de bactérias e/ou produtos metabólicos como reagentes de flotação 50

3.5.3. Bioflotação de Fosfatos 61

3.5.4. Seletividade na Bioflotação Mineral 63

3.5.5. Potencial Zeta na Bioflotação Mineral 68

3.5.6. Cinetica de Flotação Mineral 73

4. Materiais e Métodos $\quad 77$

4.1. Amostras Minerais $\quad 77$

4.2. Preparação do concentrado bacteriano e condições de cultivo 79

4.2.1. Adaptação da bactéria a substrato mineral 82

4.3. Medidas de Potencial Zeta

4.4. Ensaios de medida de ângulo de contato 84

4.5. Ensaios de Microflotação 86 
5. Resultados e Discussão 90

5.1. Preparação e caracterização dos Minerais 90

5.2. Bactéria: crescimento adaptação e caracterização 91

5.3. Potencial Zeta das amostras 94

5.4. Ângulo de Contato 100

5.5. Microflotação usando a bactéria como biorreagente 103

5.5.1. Comportamento da bactéria $R$. opacus como espumante 103

5.5.2. Ensaios exploratórios de microflotação 108

5.5.3. Influência do pH na flotabilidade mineral 109

5.5.4. Influência da concentração da Bactéria 113

5.5.5. Influência do tempo de flotação 114

5.5.6. Micrografias de Microscópio Eletrônico de varredura 115

5.5.7. Cinética de flotação mineral 117

5.5.8. Flotação com bactéria adaptada a substrato mineral 127

$\begin{array}{lr}\text { 6. Conclusões } & 133\end{array}$

7. Referências Bibliográficas 


\section{Lista de figuras}

Figura 1 - Mercado consumidor de fosfato beneficiado no ano 2009, (Anuário Mineral Brasileiro-2010, DNPM. [3]) 20

Figura 2 - Potencial Zeta de apatitas e ganga mineral em função do pH. [25] 38

Figura 3 - Potencial zeta da Wavellita [26] 38

Figura 4 - Potencial zeta das apatitas em função do $\mathrm{pH}\left(\mathrm{KNO}_{3} ; 10^{-3} \mathrm{M}\right)$. [17] 39

Figura 5 - Condição de carga zero para apatitas metodologia de Mular \& $\begin{array}{ll}\text { Roberts } & 40\end{array}$

Figura 6 - Potencial zeta da apatita na presença dos coletores aniônicos em função do pH. (Oleato: 4 × $10^{-5} \mathrm{M} ; \mathrm{KNO}_{3}: 10^{-3} \mathrm{M}$ ) [17]. 40

Figura 7 - Potencial Zeta de apatitas e ganga mineral em função do pH [25] 41

Figura 8 - Potencial Zeta de hematita e quartzo em função do pH [29] 42

Figura 9 - Típica parede celular de uma bactéria Gram-positiva [62]. 46

Figura 10 - Típica parede celular de uma bactéria Gram-negativa [62] 47

Figura 11 - Tipica classificação de bactérias, segundo a estrutura da parede celular e requerimentos nutricionais.

Figura 12 - a) Densidade de adsorção da proteína extraída da bactéria P. polymyxa; b) Flotação mineral após interação com as proteínas (Q: quartzo, P: pirita, C: calcopirita, S: esfarelita, G: Galena).

Figura 13 - a) Comportamento da flotação da pirita e calcopirita em função ao $\mathrm{pH}$ e diferentes concentrações de coletor (PIPX); b) Efeito das células na flotação de pirita e calcopirita [66].

Figura 14 - Flotação de pirita e calcopirita em presença de células de L.Ferrooxidans, usando xantato como coletor [37].

Figura 15 - Espectrograma de Infravermelho da bactéria Rhodococcus opacus e principais picos de absorbância [53].

Figura 16 - Flotabilidade da hematita (a) e quartzo (b) em função do pH e concentração da bactéria (Mesquita et al., [54]).

Figura 17 - Efeito da concentração de R. opacus na \% de flotabilidade de Magnesita [52].

Figura 18 - Efeito da concentração de R. opacus na flotabilidade de barita 
(a) e calcita (b) [53].

Figura 19 - Microflotação de apatita usando S. Carnosus como coletor, pH 9.

Figura 20 - Imagens de microscopia eletrônica de transmissão de células de P. polymyxa desenvolvidas na presença de diferentes minerais (A. S/M, B. Quartzo, C. Calcita, D. Esfarelita, E. Galena)

Figura 21 - Imagens de MEV de células Desulfovibrio desulfuricans aderidas a (a) hematita e (b) quartzo. (Prakasan e Natarajan [51])

Figura 22 - Imagens de MEV ilustrando a adesão das células de levedura aderida na calcita (a) e no quartzo (b).

Figura 23 - Potencial zeta (a); Imagem MEVde elétrons secundários (b), mostrando a interação de células de E. Coli sob asuperfície do quartzo.

Figura 24 - Potencial zeta de pirita (a) e calcopirita (b) antes e após interação com células de L. ferrooxidans,

Figura 25 - Potencial zeta para hematita antes de depois da interação com R. opacus $(\mathrm{NaCl}-0,1 \mathrm{mM})[54]$.

Figura 26 - Curvas de potencial zeta para calcita, magnesita antes e após interação com R. opacus $(\mathrm{NaCl}-0,001 \mathrm{M})$

Figura 27 - Esquema gráfico da preparação das amostras minerais. 78

Figura 28 - Colônias da bactéria R. Opacus em placa petri.

Figura 29 - Crescimento bacteriano em incubadora Shaker (CientecCT712T)

Figura 30 - Espectrofotômetro UV/Vis-1800 e Centrifuga digital.

Figura 31 - Curva de calibração da bactéria R. opacus, relação entre concentração celular e absorbância de uma suspensão celular.

Figura 32 - Zeta-Meter +4.0.

Figura 33 - Célula de acrílico do zeta-meter +4.0. 84

Figura 34 - Goniômetro Ramé Hart-inc. 85

Figura 35 - Seções polidas de amostras minerais, Quartzo e apatita.

Figura 36 - Sistema de microflotação em tubo de Hallimond, (1) Agitador magnético, (2) Bolhometro, (3) Rotâmetro, (4) Bomba de vácuocompressora, (5) Tubo de Hallimond.

Figura 37 - Concentrado celular da bactéria Rhodococcus opacus. a) células adaptadas a substrato mineral, b) células sem adaptação. 
Figura 38 - Concentrado de Rhodococcus opacus de trabalhos anteriores [79].

Figura 39 - Micrografia em MEV de células da Bactéria R. opacus.

Figura 40 - Potencial zeta de células da bactéria R. opacus. (eletrólito, $\left.\mathrm{NaCl}: 10^{-3} \mathrm{M}\right)$

Figura 41 - Potencial zeta das amostras minerais (eletrólito suporte, $\mathrm{NaCl}$ : $\left.10^{-3} \mathrm{M}\right)$.

Figura 42 - Potencial zeta do quartzo antes e após interação com a bactéria (eletrólito, $\mathrm{NaCl}: 10^{-3} \mathrm{M}$ )

Figura 43 - Potencial zeta da apatita "A" antes e após interação com a bactéria (eletrólito suporte: $\mathrm{NaCl} 10^{-3} \mathrm{M}$ )

Figura 44 - Potencial zeta da apatita "B" antes e após interação com a bactéria (eletrólito, $\mathrm{NaCl}: 10^{-3} \mathrm{M}$ ).

Figura 45 - Ângulo de contato dos minerais após contato com suspensão celular da bactéria R.opacus, (concentração celular: 0,15 g.L $\mathrm{L}^{-1}$; tempo de contato: 5 minutos).

Figura 46 - Ângulo de contato dos minerais após contato com suspensão celular da bactéria R.opacus, (concentração celular: 0,15 g. $\mathrm{L}^{-1}$; tempo de contato: 5 minutos).

Figura 47 - Ângulo de contato dos minerais após contato com suspensão celular da bactéria R.opacus, (concentração celular: 0,15 g. $\mathrm{L}^{-1}$; tempo de contato: 5 minutos).

Figura 48 - Espuma formada pela suspensão bacteriana a diferentes valores de pH, concentração: 0,15 g. $\mathrm{L}^{-1}$. (a) $\mathrm{pH} 3$, (b) $\mathrm{pH} 5$, (c) $\mathrm{pH} 7$, (d) $\mathrm{pH} 9$, (e) $\mathrm{pH} 11$.

Figura 49 - Tensão superficial da suspensão celular de R. opacus em função do pH. (concentração celular: 0,15 g. $\mathrm{L}^{-1}$ ).

Figura 50 - Tensão superficial da suspensão celular de R.opacus em função da concentração; pH 5.

Figura 51 - Tubo de Hallimond modificado com diferentes alturas para minimizar o arraste de partículas, (a) sem tubo prolongador $130 \mathrm{~mL}$, (b) Tubo prolongador de $50 \mathrm{~mm}$; $160 \mathrm{~mL}$, (c) Tubo prolongador de $100 \mathrm{~mm}$, $190 \mathrm{ml}$.

Figura 52 - Flotabilidade da apatita "B" em função do pH; tamanho de 
partículas $\left(75\right.$ - 106) $\mu \mathrm{m}$, eletrólito, $\mathrm{NaCl} 10^{-3} \mathrm{M}$, tempo de flotação, 2 minutos.

Figura 53 - Flotabilidade da apatita "A" em função do pH; tamanho de partículas $\left(75\right.$ - 106) $\mu \mathrm{m}$, eletrólito, $\mathrm{NaCl} 10^{-3} \mathrm{M}$, tempo de flotação, 2 minutos.

Figura 54 - Flotabilidade do quartzo em função do $\mathrm{pH}$; tamanho de partículas $\left(75\right.$ - 106) $\mu \mathrm{m}$, eletrólito, $\mathrm{NaCl} 10^{-3} \mathrm{M}$, tempo de flotação, 2 minutos.

Figura 55 - Flotabilidade dos minerais em função da concentração celular (pH 5, tamanho de partícula, $(106-75) \mu \mathrm{m}$, eletrólito $\mathrm{NaCl}: 10^{-3} \mathrm{M}$, tempo de flotação: 2 minutos)

Figura 56 - Flotabilidade dos minerais em função do tempo, pH 5, tamanho de partícula: $75 \mu \mathrm{m}-106 \mu \mathrm{m}$,eletrólito $\mathrm{NaCl}: 10^{-3} \mathrm{M}$

Figura 57 - Imagem de MEV de células da bactéria R. opacus na superfície da apatita "B" após flotação.

Figura 58 - Imagen de MEV de células da bactéria R. opacus na superfície da apatita "A" após flotação.

Figura 59 - Imagem de MEV de células da bactéria R. opacus na superfície do quartzo após flotação.

Figura 60 - Flotabilidade da apatita “A”em função do tempo a diferentes tamanhos de partícula, pH 5, concentração celular: 0,2 g.L ${ }^{-1}$. (Tirar linhas) Figura 61 - Modelo de primeira ordem - Flotabilidade da apatita “A”, pH 5, concentração celular: 0,2 g.L. $\mathrm{L}^{-1}$.

Figura 62 - Cinética da Flotabilidade da apatita "A" usando a bactéria R. opacus, com diferentes tamanho de partículas.

Figura 63 - Flotabilidade da apatita "B" em função do tempo a diferentes tamanhos de partículas, $\mathrm{pH}$ 5, concentração celular: 0,15 g. $\mathrm{L}^{-1}$.

Figura 64 - Modelo de primeira ordem - Flotabilidade de apatita "B", pH 5, concentração celular: 0,15 g.L. $\mathrm{L}^{-1}$.

Figura 65 - Cinética da Flotabilidade da apatita "B" usando a bactéria R. opacus, com diferentes tamanho de partículas.

Figura 66 - Flotabilidade de quartzo em função do tempo a diferentes tamanhos de partículas, pH 5, concentração celular: 0,15 g. $\mathrm{L}^{-1}$.

Figura 67 - Modelo de Primeira ordem - Flotabilidade de quartzo, pH 5, 
concentração celular: 0,15 g.L $\mathrm{L}^{-1}$.

Figura 68 - Modelo de segunda ordem - Flotabilidade de quartzo, pH 5, concentração celular: $0,15 \mathrm{~g} \cdot \mathrm{L}^{-1}$

Figura 69 - Cinética da Flotabilidade da quartzo usando a bactéria R. opacus, com diferentes tamanho de partículas.

Figura 70 - Espuma gerada pela bactéria Rhodococcus opacus adaptada a substrato mineral. A) $\mathrm{pH} \mathrm{3,} \mathrm{b)} \mathrm{pH} 5$, c) $\mathrm{pH} 7$, d) $\mathrm{pH} 9$, e) $\mathrm{pH} 11$, Concentração bactéria, 0,15 g. $\mathrm{L}^{-1}$.

Figura 71 - Tensão superficial de células da bactéria R. opacus sem e com adaptação a substrato mineral.

Figura 72 - Microflotação da apatita "A" usando a bactéria R. opacus adaptada a substrato mineral; concentração celular: 0,20 g.L $\mathrm{L}^{-1}$

Figura 73 - Microflotação de quartzo usando a bactéria R. opacus adaptada a substrato mineral; concentração celular: 0,15 g. $\mathrm{L}^{-1}$. 


\section{Lista de tabelas}

Tabela 1 - Reservas e produção de rocha fosfática no mundo (Fonseca, 2011. [2])

Tabela 2 - Nomes existente, aprovados e fórmulas para minerais dentro do supergrupo da apatita.

Tabela 3 - Reservas Minerais de rocha fosfática 2009 (DNPM, Anuário Mineral Brasileiro-2010) [3]

Tabela 4 - Composição típica dos minérios de Tapira MG [5]

Tabela 5 - Composição de alguns óleos vegetais e animais (ácidos graxos)

Tabela 6 - Reagentes usados na flotação de minérios fosfáticos no Brasil [19]

Tabela 7 - Bactérias usadas em biobeneficiamento mineral

Tabela 8 - Principais grupos ionizáveis nos componentes macromoleculares biológicos susceptíveis de participar na ligação de metais pesados

Tabela 9 - Valores do PIE de diversos minerais antes e após interação com a bactéria $P$. polymyxa

Tabela 10 - Composição da parede celular da Bactéria R. opacus [53]. 56

Tabela 11 - Atribuição geral de bandas na bactéria [65]

Tabela 12 - Flotação de dolomita com B. suptilis (Oleato de sódio, 10 mg/L)

Tabela 13 - Flotação de apatita com B. suptilis (Oleato de sódio, 40 mg/L) 62

Tabela 14 - Geração de biorreagentes durante o crescimento da P.polymyxa[35].

Tabela 15 - Resumo dos ensaios de flotação do sistema hematita-quartzo usando a bactéria $D$. desulfuricans.

Tabela 16 - Separação de calcita e quartzo através de flotação induzida por micróbios.

Tabela 17 - Principais fatores determinantes na probabilidade da mineralização da bolha[74]

Tabela 18 - Modelos cinéticos mais comuns da flotação mineral.

Tabela 19 - frações granulométricas dos minerais para cada um dos ensaios realizados 
Tabela 20 - Meio de cultivo utilizado na cultura bacteriana.

Tabela 21- Condições empregadas na microflotação mineral

Tabela 22 -Parâmetros utilizados na determinação da cinética de microflotação mineral usando a bactéria R.opacus como biorreagente.

Tabela 23 - Composição mineralógica das amostras de mineral via DRX (Difração de Raios X)

Tabela 24 - Análise semiquantitativa das amostras minerais via espectrômetro por fluorescência de raios X Epsilon (EDS)

Tabela 25 - Valores de tensão superficial de diferentes microrganismos na interface ar/água (no valor da CMC do biosurfactante)

Tabela 26 - Mínimos de Tensão superficial de $\beta$-glucosidade e celulase

Tabela 27 - Flotabilidade das amostras minerais usando tubo de Hallimond modificado com diferentes alturas

Tabela 28 - Constantes cinéticas da microflotação de apatita “ $A$ ” usando a bactéria $R$. opacus em função do tamanho de partícula.

Tabela 29 - Constantes cinéticas da microflotação de apatita “ $B$ ” usando a bactéria $R$. opacus em função do tamanho de partícula.

Tabela 30 - Constantes cinéticas da microflotação de quartzo usando a bactéria $R$. opacus em função do tamanho de partícula. 